\title{
PENGARUH CITRA BPR, KUALITAS PELAYANAN, NILAI NASABAH, KEPERCAYAAN DAN KEPUASAN NASABAH TERHADAP \\ LOYALITAS NASABAH TABUNGAN PADA BANK PERKREDITAN RAKYAT (BPR) LUGAS DANA MANDIRI CABANG SOLOK
}

\author{
Dettrita Yetti, Rian Hidayat, Wati \\ Program Studi Pendidikan Ekonomi STKIP PGRI Sumatera Barat \\ dettritay@gmail.com
}

\begin{abstract}
This research aims to analyze: 1) the influence of BPR pictures on honest loyalists. 2) The effect of service quality on loyal customers. 3) The impact of customer value in customer loyalty. 4) The influence of customer trust on customer loyalty. 5) The result of customer satisfaction on customer loyalty. 6) The impact of quality service on customer satisfaction. 7) The influence of customer value in customer satisfaction. Research results are: (1) BPR images have a positive and significant impact on customer loyalty; (2) Service quality has a positive and significant impact on customer loyalty; (3) Customer value has a positive and significant impact on customer loyalty Significant impact, (4) trust has a positive and important impact on customer loyalty, (5) customer satisfaction has a positive and important impact on customer loyalty, (6) service quality has a positive and important impact on customer satisfaction (7) Customer value has a positive and significant impact on customer satisfaction.

Keywords: BPR Image, Service Quality, Customer Value, Trust, Customer Satisfaction, Customer Loyalt

\section{PENDAHULUAN}

Pada sekitar tahun belakang ini banyak sekali persaingan yang terjadi di dunia usaha dan persaingan tersebut sangat ketat dimana setiap perusahaan di tuntut untuk dapat memenuhi kebutuhan masyarakat, sehingga dapat mempermudah masyarakat dalam melakukan aktifitasnya. Suatu perusahan juga harus mampu menarik masyarakat agar mau bergabung dan menyukai perusahaan tersebut. Salah

satu perusahaan yang mempermudah masyarakat dalam melakukan transaksi adalah Bank.

Bank merupakan suatu perusahaan atau suatu lembaga yang berwenang di bidang jasa keuangan, yang umumnya dikenal sebagai tempat menyimpan dan meminjam uang.

Dalam membangun dan
menumbuhkan pelanggan setia,
perusahaan perlu fokus pada faktor-
faktor kunci yang memotivasi mereka.
\end{abstract}


Menurut Krismanto dalam corporate identity. Dalam Satriyanti (2012:173), terdapat variable meningkatkan suatu citra perusahaan yang bisa mempengaruhi loyalitas (bank), bank tersebut harus bisa andal Nasabah, yaitu penanganan komplain, dan industri mempunyai tugas sosial.

kualitas pelayanan, citra dan kepuasan. Menurut Laksana dalam Satriyanti Sedangkan menurut Zikmund dan (2012:174) Kualitas diartikan sebagai Vanessa, dalam Saputro dkk, tingkat kualitas yang diharapkan dan (2017:154), loyalitas pelanggan di bervariasi yang diatur dalam pengaruhi lima hal penting, termasuk pencapaian kualitas tersebut untuk kepuasan, empati, kepercayaan, memenuhi kebutuhan pelanggan.

kesederhanaan, dan pengalaman Menurut Levesque and Dougall dengan perusahaan. Kelima faktor dalam Kotler (2016:85) perbandingan tesebut membentuk loyalitas nasabah antara setiap keuntungan yang yang didasari perspektif sikap dan didapatkan oleh pelanggan dengan perilaku.

baiaya pengorbanan yang dibebankan

Menurut studi Butz dan Goodstein dalam Hidayat dkk (2009:59), disebut nilai.

Menurut Barnes dalam Khotimah komunikasi dua arah antara nasabah (2012:44) keyakinan bahwa seseorang dengan bank di mana hubungan akan menemukan apa yang ia inginkan tercipta setelah nasabah tahu dan pada diri orang lain, dan bukan apa memberikan penilaian positif terhadap yang ia takutkan yakni kepercayaan.

produk atau layanan yang ditawarkan. Menurut Tjiptono dalam Irda dan Kesimpulan tersebut mengarah pada Desiyanti (2013) Kepuasan hubungan antara nilai bagi nasabah mengartikan "upaya pemenuhan dengan kepuasan nasabah serta sesuatu" maupun "membuat sesuatu loyalitas nasabah menggambarkan nilai memadai”. Menurut Kotler dalam Irda bagi nasabah.

\& Desiyanti (2013) untuk mengukur

Harrison dalam Purba (2017) Informasi lengkap tentang perusahaan memiliki empat komponen, termasuk karakteristik, reputasi, nilai, dan penataan tempat. 


\section{METODE PENELITIAN}

Bersumber pada persoalan dan arahan yang perlu dicapai dan model riset yang digunakan yaitu deskriptif dan asosiatif. Penelitian akan dilakukan pada Bank Perkreditan Rakyat (BPR) Lugas Dana Mandiri Cabang Solok dilaksanakan pada bulan januari 2020. Populasinya yaitu nasabah yang meenggunakan tabungan simpeda. Menurut (Sugiyono, 2012:120) bagian dari jumlah dan karakteristik yang dimiliki oleh populasi tersebut yaitu sampel. Cara riset ini mengunakan Purposive sampel dan kriteria adalah nasabah tabungan Bank Perkreditan Rakyat (BPR) Lugas Dana Mandiri Cabang Solok. Sampel pada penelitian adalah sebanyak 120 responden.

\section{HASIL DAN PEMBAHASAN}

Analisis Jalur (Part Analysis)

1) Analisis Jalur Sub Struktur I

Penjabaran Jalur bagian susunan I menguji Pengaruh Kualitas Pelayanan dan Nilai Nasabah kepada Kepuasan Nasabah Tabungan Bank Perkreditan Rakyat (BPR) Lugas Dana Mandiri Cabang Solok. Berikut hasil pengolahan data pada susunan I :

Tabel 1. Hasil Analisis Jalur Sub Struktur I

\begin{tabular}{lllccc}
\hline \multicolumn{1}{c}{$\begin{array}{c}\text { Variabel } \\
\text { Endogen }\end{array}$} & Variabel Eksogen & $\begin{array}{c}\text { Koefisien } \\
\text { Jalur }\end{array}$ & thitung & Sig & Ket \\
\hline $\begin{array}{l}\text { Kepuasan } \\
\text { Nasabah }\left(\mathrm{X}_{5}\right)\end{array}$ & $\begin{array}{l}\text { Kualitas } \\
\text { Pelayanan }\left(\mathrm{X}_{2}\right)\end{array}$ & 0,683 & 10,731 & 0,000 & Signifikan \\
& NilaiNasabah $\left(\mathrm{X}_{3}\right)$ & 0,520 & 8,169 & 0,000 & Signifikan
\end{tabular}

Asal: Olahan Data Primer, 2020

Berdasarkan analisis data tersebut menentukan maka kualitas pelayanan berdampak eksplisit dan penting kepada kepuasan nasabah $\left(\mathrm{X}_{5}\right)$ menunjukkan koefisien jalur $\mathrm{PX}_{5} \mathrm{X}_{2}=$ 0,683 . Nilai $t_{\text {hitung }}=10,731$ dengan tingkat level sig $0,000<0,05$. Ini memberikan gambaran bahwa apabila kualitas pelayanan yang ditawarkan baik hingga kepuasan nasabah dalam menabung juga akan lebih baik.

Hasil analisis jalur pengaruh variabel nilai nasabah $\left(\mathrm{X}_{3}\right)$ terhadap variabel kepuasan nasabah $\left(\mathrm{X}_{5}\right)$ menunjukkan koefisien jalur $\mathrm{PX}_{5} \mathrm{X}_{3}=$ 0,520. Nilai $t_{\text {hitung }}=8,169$ dengan tingkat level sig $0,000<0,05$. Berdasarkan analisis data tersebut membuktikan bahwa nilai nasabah 
berpengaruh signifikan terhadap kepuasan nasabah tabungan pada Bank Perkreditan Rakyat (BPR) Lugas Dana Mandiri Cabang Solok. Ini memberikan gambaran bahwa apabila nilai nasabah yang ditawarkan baik maka kepuasan nasabah dalam menabung juga akan lebih baik.

Untuk melihat besarnya kontribusi atau koefisien determinasi $\left(\mathrm{R}_{\text {square }}=\mathrm{R}^{2} \mathrm{X}_{5} \mathrm{X}_{2} \mathrm{X}_{3}\right)$ kualitas pelayanan dan nilai nasabah terhadap kepuasan nasabah tabungan pada Bank Perkreditan Rakyat (BPR) Lugas Dana Mandiri Cabang Solok. Untuk melihat besarnya kontribusi atau, diperlihatkan oleh nilai R Square sebesar 0,556 atau $55,6 \%$. Ini berarti kualitas pelayanan dannilai nasabah terhadapkepuasan nasabah dapat dijelaskan sebesar $55,6 \%$. Sedang sisanya $44,4 \%$ dipengaruhi oleh variabel lain yang tidak diteliti dalam penelitian ini.
Besar koefisien pengaruh variabel lain terlihat dari nilai koefisien residual (Px5\&2) dapat dihitung sebagai berikut:

$$
\begin{aligned}
& \text { Px5e1 }=\sqrt{1-R^{2} x_{5} x_{2} x_{3}} \\
& =\sqrt{1-0,556} \\
& =0,666 \times 0,666 \\
& =0,444
\end{aligned}
$$

Hasil analisis data pada sub struktur I dapat dimasukan ke dalam persamaan jalur sebagai berikut:

$$
\begin{aligned}
& \mathrm{X}_{5}=\mathrm{PX}_{5 \mathrm{X} 2} \mathrm{X}_{2}+\mathrm{P}_{\mathrm{X} 5 \mathrm{X}_{3} \mathrm{X}_{3}} \\
& \mathrm{X}_{5}=0,683 \mathrm{X}_{2}+0,520 \mathrm{X}_{3}
\end{aligned}
$$

2) Analisis Jalur Sub struktur II

Kajian Jalur susunan dua pada riset mengevaluasi dampak Citra BPR, Kualitas Pelayanan, Nilai Nasabah, Kepercayaan dan Kepuasan Nasabah Terhadap Loyalitas Nasabah Tabungan

\begin{tabular}{|c|c|c|c|c|c|}
\hline $\begin{array}{l}\text { Variabel } \\
\text { Endogen }\end{array}$ & Variabel Eksogen & $\begin{array}{l}\text { Koefisien } \\
\text { Jalur }\end{array}$ & $t_{\text {hitung }}$ & Sig & Ket \\
\hline \multirow{5}{*}{$\begin{array}{l}\text { Loyalitas } \\
\text { Nasabah } \\
\text { (Y) }\end{array}$} & Citra BPR $\left(\mathrm{X}_{1}\right)$ & 0,335 & 6,340 & 0,000 & Signifikan \\
\hline & Kualitas Pelayanan & 0,277 & 4,977 & 0,000 & Signifikan \\
\hline & Nilai Nasabah $\left(\mathrm{X}_{3}\right)$ & 0,301 & 6,080 & 0,000 & Sig \\
\hline & Kepercayaan $\left(\mathrm{X}_{4}\right)$ & 0,295 & 7,436 & 0,000 & Signifikan \\
\hline & $\begin{array}{l}\text { Kepuasan Nasabah } \\
\left(\mathrm{X}_{5}\right)\end{array}$ & 0,254 & 3,849 & 0,000 & Signifikan \\
\hline
\end{tabular}
Pada Bank Perkreditan Rakyat (BPR) Lugas Dana Mandiri Cabang Solok. Berikut hasil pengolahan data pada susunan II:

Tabel 2. Hasil Analisis Jalur Sub Struktur II

Sumber: Olahan Data Primer, 2020. 
Dari hasil analisis data tersebut menentukan maka citra $\operatorname{BPR}\left(\mathrm{X}_{1}\right)$ terhadap variabel loyalitas nasabah (Y) menunjukkan koefisien jalur $\mathrm{PYX}_{1}=0,335$. Nilai thitung $=6,340$ dengan tingkat level sig 0,000<0,05. Berdasarkan analisis data tersebut menunjukkan yakni gambaran BPR berdampak penting pada kesetiaan nasabah tabungan pada Bank Perkreditan Rakyat (BPR) Lugas Dana Mandiri Cabang Solok. Ini memberikan gambaran bahwa apabila citra yang diberikan BPR baik maka kesetiaan nasabah akan meningkat.

Hasil analisis jalur pengaruh variabel kualitas pelayanan $\left(\mathrm{X}_{2}\right)$ terhadap variabel loyalitas nasabah (Y) menunjukkan koefisien jalur $\mathrm{PYX}_{2}=0,277$. Nilai $\mathrm{t}_{\text {hitung }}=4,977$ dengan tingkat level sig 0,000 < 0,05 . Berdasarkan analisis data tersebut menunjukkan yakni mutu jasa berdampak penting pada kesetiaan pengguna simpanan Bank Perkreditan Rakyat (BPR) Lugas Dana Mandiri Cabang Solok. Ini memberikan gambaran bahwa apabila kualitas pelayanan yang diberikan BPR baik maka loyalitas nasabah akan meningkat.

Hasil analisis jalur pengaruh fleksibel kadar pengguna $\left(\mathrm{X}_{3}\right)$ kepada kesetiaan nasabah (Y) menunjukkan koefisien jalur $\mathrm{PYX}_{3}=$ 0,301 . Nilai $t_{\text {hitung }}=6,080$ dengan tingkat level sig $0,000<0,05$. Berdasarkan analisis data tersebut menunjukkan bahwa nilai nasabah berpengaruh signifikan terhadap loyalitas nasabah tabungan pada Bank Perkreditan Rakyat (BPR) Lugas Dana Mandiri Cabang Solok.Ini memberikan gambaran bahwa apabila nilai nasabah yang diberikan BPR baik maka loyalitas nasabah akan meningkat.

Hasil analisis jalur pengaruh variabel kepercayaan $\left(\mathrm{X}_{4}\right)$ terhadap variabel loyalitas nasabah (Y) menunjukkan koefisien jalur $\mathrm{PYX}_{4}=$ 0,295 . Nilai $t_{\text {hitung }}=7,436$ dengan tingkat level sig $0,000<0,05$. Berdasarkan analisis data tersebut menunjukkan bahwa kepercayaan berdampak penting pada kesetian pengguna tabungan pada Bank Perkreditan Rakyat (BPR) Lugas Dana Mandiri Cabang Solok. Ini memberikan gambaran bahwa 
apabila kepercayaan yang diberikan BPR baik maka loyalitas nasabah akan meningkat.

Hasil analisis jalur pengaruh variabel kepuasan nasabah $\left(\mathrm{X}_{5}\right)$ terhadap variabel loyalitas nasabah (Y) menunjukkan koefisien jalur $\mathrm{PYX}_{5}=0,254$. Nilai thitung $=3,849$ dengan tingkat level sig $0,000<$ 0,05 . Berdasarkan analisis data tersebut menunjukkan kesenangan pengguna berdampak penting pada kesetiaan nasabah tabungan pada Banc Perkreditan Rakyat (BPR) Lugas Dana Mandiri Cabang Solok. Ini memberikan gambaran bahwa apabila kepuasan nasabah yang diberikan BPR baik maka loyalitas nasabah akan meningkat.

Untuk melihat besarnya kontribusi atau koefisien determinasi $\left(\mathrm{R}_{\text {square }}=\mathrm{R}^{2} \mathrm{YX}_{1} \mathrm{X}_{2} \mathrm{X}_{3} \mathrm{X}_{4} \mathrm{X}_{5}\right) \quad$ citra BPR, mutu jasa, kadar pengguna, kepercayaan beserta kepuasan nasabah pada kesetiaan nasabah tabungan pada Banc Perkreditan Rakyat (BPR) Lugas Dana Mandiri Cabang Solok. Untuk melihat besarnya kontribusi atau, diperlihatkan oleh nilai $\mathrm{R}$ Square 0,842 atau $84,2 \%$. Ini berarticitra
BPR, kualitas pelayanan, kadar pengguna, kepercayaan beserta kesenangan nasabah terhadap loyalitas nasabah dapat dijelaskan sebesar 84,2\%. Sedang sisanya $15,8 \%$ dipengaruhi variabel lain yang tidak diteliti dalam penelitian. Besar koefisien akibat fleksibel lain terlihat dari nilai koefisien residual (PY\&2) dapat dihitung sebagai berikut :

$$
\begin{aligned}
\text { PxYe2 } & =\sqrt{1-R^{2} y x_{1} x_{2} x_{3} x_{4} x_{5}} \\
= & \sqrt{1-0,842} \\
= & 0,397 \times 0,397 \\
= & 0,158
\end{aligned}
$$

Hasil persamaan jalur pada sub struktur II sebagai berikut :

$\mathrm{Y}=\mathrm{P}_{\mathrm{YX} 1} \mathrm{X}_{1}+\mathrm{P}_{\mathrm{YX} 2} \mathrm{X}_{2}+\mathrm{P}_{\mathrm{YX} 3} \mathrm{X}_{3}+$ $\mathrm{P}_{\mathrm{YX}} \mathrm{X}_{4}+\mathrm{P}_{\mathrm{YX}} \mathrm{X}_{5}$

$\mathrm{Y}=0,335 \mathrm{X}_{1}+0,277 \mathrm{X}_{2}+0,301 \mathrm{X}_{3}+$ $0,295 X_{4}+0,254 X_{5}$

Pengaruh Citra BPR Pada Kesenangan Nasabah simpanan di Bank Perkreditan Rakyat (BPR) Lugas Dana Mandiri Cabang Solok.

Berdasarkan hasil pengujian hipotesis pertama bahwa Citra BPR berpengaruh signifikan terhadap Loyalitas Nasabah tabungan Bank Perkreditan Rakyat Lugas Dana Mandiri Cabang Solok. Koefisien jalur citra BPR terhadap loyalitas 
nasabah ( $\mathrm{P}_{\mathrm{x} 5 \mathrm{x} 1}$ ) yaitu 0,335 . Nilai koefisien ini signifikan karena nilai $t_{\text {hitung }}=6,340 \quad>t_{\text {tabel }} \quad 0,05 \quad(1,66)$ dengan tingkat level sig $0,000<0,05$. Jadi bisa disimpulkan akibat langsung citra BPR pada loyalitas nasabah adalah sebesar 0,112 atau11,2\%.

Temuan penelitian ini sesuai dengan pendapat (Istijano, 2005) Perusahaan dengan citra atau reputasi yang baik akan mendorong konsumen untuk membeli produk yang ditawarkan, meningkatkan daya saing, meningkatkan moral karyawan, dan meningkatkan loyalitas pelanggan.

Dampak Kualitas Layanan Terhadap Nasabah Setia Simpanan Di BPR Lugas Dana Mandiri Cabang Solok.

\section{Kualitas}

pelayanan

berdampak penting kepada setia mendanai Bank Kredit Rakyat Lugas Dana Mandiri Cabang Solok. Koefisien jalur pelayanan yang baik pada loyalitas pengguna $\mathrm{PYX}_{2}$ adalah 0,277 .

Pengaruh kualitas pelayanan terhadap loyalitas nasabah sebesar 0,277 nilai sig $0,000<0,05$. Dikatakan bahwa pengaruh langsung kualitas pelayanan terhadap loyalitas nasabah adalah sebesar 0,077 atau $7,7 \%$.

Temuan penelitian ini sesuai dengan pendapat Wyckof dan Tjiptono dalam Chrisna \& Artanti (2013) Pelayanan yang baik adalah posisi terbaik yang diharapkan dan diatur tingkat yang terbaik untuk memuaskan kebutuhan pelanggan.

Pengaruh Nilai Nasabah Terhadap Loyalitas Pengguna Simpanan Di BPR Lugas Dana Mandiri Cabang Solok.

Niilai nasabah berdampak penting kepada loyalitas nasabah tabungan Bank Perkreditan Rakyat Lugas Dana Mandiri Cabang Solok. Koefisien jalur nilai nasabah terhadap loyalitas nasabah $\mathrm{PYX}_{3}$ adalah $\quad 0,301$ maka $\mathrm{H}_{0}$ ditolak $\mathrm{H}_{\mathrm{a}}$ diterima, Pengaruh kadar pengguna pada kesetiaan nasabah sebesar 0,301 nilai signifikan $0,000<$ a 0,05. Dikatakan bahwa pengaruh langsung nilai nasabah terhadap loyalitas nasabah adalah sebesar 0,091atau $9,1 \%$.

Hasil penelitian ini sejalan dengan pandangan dalam Zeithaml Tinik Sugsiati (2012) bahwa nilai pelanggan didasarkan pada evaluasi 
konsumen secara keseluruhan atas kegunaan barang atau jasa berdasarkan kesan yang diberikan.

Pengaruh Kepercayaan Kepada Kesetiaan Pengguna Simpanan Di BPR Lugas Dana Mandiri Cabang Solok

Kepercayaan berdampak penting kepada loyalitas nasabah tabungan Bank Perkreditan Rakyat Lugas Dana Mandiri Cabang Solok. Koefisien jalur kepercayaan terhadap loyalitas nasabah $\mathrm{PYX}_{4}$ adalah 0,295 maka $\mathrm{H}_{0}$ ditolak $\mathrm{H}_{\mathrm{a}}$ diterima, Pengaruh kepercayaan terhadap loyalitas nasabah sebesar 0,295 nilai sig $0,000<\alpha 0,05$. Dikatakan bahwa pengaruh langsung kepercayaan terhadap loyalitas nasabah adalah sebesar 0,087 atau $8,7 \%$

Temuan penelitian ini sejalan dengan pandangan Maria dalam Syaiful \& Khuzaini (2015) maka kepercayaan merupakan dasar daribisnis, karena jika kedua belah pihak dalam suatu transaksi saling percaya maka akan terjadi transaksi.

Pengaruh Kepuasan Nasabah Pada Kesetiaan Nasabah Simpanan di BPR Lugas Dana Mandiri Cabang Solok
Kepuasan nasabah berdampak penting kepada loyalitas nasabah tabungan bank perkreditan rakyat lugas dana mandiri cabang solok. Koefisien jalur kepuasan nasabah terhadap loyalitas nasabah $\mathrm{PYX}_{5}$ adalah 0,254 hingga $\mathrm{H}_{0}$ ditolak $\mathrm{H}_{\mathrm{a}}$ diterima, Pengaruh kepuasan nasabah terhadap loyalitas nasabah sebesar 0,254 nilai sig $0,000<\alpha \quad 0,05$. Dikatakan bahwa pengaruh langsung kepuasan nasabah terhadap loyalitas nasabah adalah sebesar 0,064 atau $6,4 \%$.

Temuan penelitian ini sesuai dengan pendapat Kotler dalam Sukaatmadja (2014) kepuasan pelanggan adalah perasaan senang atau kecewa seseorang yang muncul setelah membandingkan antara harapan terhadap kenyataan yang diperoleh. Kepuasan atau rasa senang yang tinggi menciptakan ikatan emosional dengan merek atau perusahaan yang bersangkutan.

Pengaruh Kualitas Layanan Pada Kepuasan Pengguna Simpanan di BPR Lugas Dana Mandiri Cabang Solok

Kualitas pelayanan berdampak penting kepada kesenangan nasabah 
tabungan pada bank perkreditan rakyat lugas dana mandiri cabang solok. Koefisien pelayanan yang baik untuk pelanggan yang puas $\mathrm{PX}_{5} \mathrm{X} 2$ adalah 0,683 maka $\mathrm{H}_{0}$ ditolak $\mathrm{H}_{\mathrm{a}}$ diterima, Pengaruh kualitas pelayanan terhadap kepuasan nasabah sebesar 0,683 nilai $\operatorname{sig} 0,000<\alpha 0,05$.

Temuan penelitian ini sesuai dengan pendapat Quaquab dkk, dalam Bernadus (2019) yang menyatakan kualitas layanan berpengaruh signifikan terhadap kepuasan nasabah. Ini menyiratkan bahwa semakin tinggi kualitas layanan, maka semakin tinggi kepuasan nasabah. Kualitas jasa atau layanan dimulai dari kebutuhan nasabah dan berakhir dengan kepuasan, hubungan tersebut secara teoritis maupun empiris adalah positif.

Pengaruh Nilai Nasabah Terhadap Kepuasan Nasabah Tabungan Pada Bank Perkreditan Rakyat (BPR) Lugas Dana Mandiri Cabang Solok

Nilai nasabah dampak penting kepada kepuasan nasabah tabungan pada Bank Perkreditan Rakyat (BPR) Lugas Dana Mandiri
Cabang Solok. Hasil analisis jalur pengaruh variabel nilai nasabah $\left(\mathrm{X}_{3}\right)$ terhadap variabel kepuasan nasabah $\left(\mathrm{X}_{5}\right)$ menunjukkan koefisien jalur $\mathrm{PX}_{5} \mathrm{X}_{3}=0,520$. Nilai thitung $=8,169$.

Hasil penelitian ini sejalan dengan pandangan Kotler (2007) bahwa customer value merupakan selisih antara total customer value dan total customer cost.

\section{KESIMPULAN}

$$
\begin{aligned}
& \text { Bersumber } \\
& \text { persoalan dan permasalahan } \\
& \text { maka pengkajian yang } \\
& \text { dilakukan, kudah } \\
& \text { disimpulkan seperti: } \\
& \text { 1. Citra BPR berdampak positif dan } \\
& \text { penting kepada loyalitas nasabah } \\
& \text { tabungan pada Bank Perkreditan } \\
& \text { Rakyat (BPR) Lugas Dana } \\
& \text { Mandiri Cabang Solok. }
\end{aligned}
$$

2. Kualitas pelayanan berdampak positif dan penting kepada loyalitas nasabah tabungan pada Bank Perkreditan Rakyat (BPR) Lugas Dana Mandiri Cabang Solok.

3. Nilai nasabah berdampak positif dan penting kepada loyalitas nasabah tabungan pada Bank 
Perkreditan Rakyat (BPR) Lugas

Dana Mandiri Cabang Solok.

4. Kepercayaan berdampak positif dan penting kepada loyalitas nasabah tabungan pada Bank Perkreditan Rakyat (BPR) Lugas Dana Mandiri Cabang Solok.

5. Kesenangan nasabah berdampak jelas dan penting kepada kesetiaan nasabah tabungan di BPR Lugas Dana Mandiri Cabang Solok.

6. Kualitas pelayanan berdampak positif dan penting kepada kepuasan nasabah tabungan pada Bank Perkreditan Rakyat (BPR) Lugas Dana Mandiri Cabang Solok.

7. Nilai nasabah berdampak positif dan penting kepada kepuasan nasabah tabungan pada Bank Perkreditan Rakyat (BPR) Lugas Dana Mandiri Cabang Solok.

\section{DAFTAR PUSTAKA}

Chrisna Dan Artanti (2013). Pengaruh Kualitas Layanan Dan Penanganan Keluhan Terhadap Loyalitas Nasabah (Studi Pada Nasabah Pt. Bank Rakyat Indonesia (Persero) Tbk. Cabang Nganjuk).Jurnal Ilmu Manajemen, 1, 11051116.
Hidayat, R (2009). Pengaruh Kualitas Layanan, Kualitas Produk Dan Nilai Nasabah Terhadap Kepuasan Dan Loyalitas Nasabah Bank Mandiri. Jurnal Manajemen Dan Wirausaha, 11(1), 59-72. Https://Doi.Org/10.9744/Jmk.1 1.1.Pp.59-72

Irda, Dkk (2013). Pengaruh Citra Bank Terhadap Loyalitas Nasabah Bank Mandiri Cabang Sudirman Padang Dengan Kepuasan Sebagai Variabel Intervening.Jurusan Manajemen, Fakultas Ekonomi, Universitas Bung Hatta.

Khotimah, K (2016)Pengaruh Kualitas Layanan Terhadap Loyalitas Pelanggan Melalui Kepuasan Pelanggan Sebagai Variabel Intervening (Studi Pada Pelanggan Dunkin' Donuts Di Surabaya Dan Sidoarjo).Bisma - Bisnis Dan Manajemen, 9 No 1, 43-55.

Kotler (2016)Analisis Pengaruh
Nilai Pelangan Terhadap
Kepuasan Pelanggan Dan
Dampaknya Pada Loyalitas
Pelanggan (Survei Pada
Pengguna Sepeda Motor
Honda Vario All Variant Di
Service Center Honda Ahass
Sukma Motor Jalan Sigura-
Gura Barat Kota Malang).
Manajemen Pemasaran.
Dialihbahasakan Oleh: Bob
Sabran.Jakarta:Erlangga.,
39(1), 87.

Kotler, Philip. 2007. Manajemen 
Pemasaran. Jakarta: PT Malanan Jaya Cemerlang.

Purba, R. P. (2017)Pengaruh Citra Perusahaan Terhadap Loyalitas Pelanggan (Studi Kasus Pt. Bintang Utara Perwakilan Dolok Sanggul). Jom Fisip, 4(2), 1-15.

Saputro, D. (2017)Pengaruh Kepuasan Pelanggan, Kepercayaan Pelanggan Dan Switching Barriers Terhadap Loyalitas Pelanggan (Studi Kasus Pada Toko Ogan Malang).E - Jurnal Riset Manajemenprodi Manajemen, 0(November 2016), 124-135. Https://Doi.Org/10.1123/Ijsb.8. 1.1

Satriyanti Oktaviani, E. (2012) Pengaruh Kualitas Layanan, Kepuasan Nasabah Dan Citra Bank Terhadap Loyalitas Nasabah Bank Muamalat Di Surabaya.Journal Of Business And Banking, 2(2), 171. Https://Doi.Org/10.14414/Jbb. V2i2.172

Syaiful, Mochamad, Khuzaini. 2015. Pengaruh Relationship Marketing, Komitmen dan Kepercayaan Terhadap Loyalitas Pelanggan Auto 2000 Sungkono. "Jurnal Ilmu dan Riset Manajemen". Vol. 4,. No. 12.

Sugiati, Tinik, Armanu Thoyib, Djumilah Hadiwidjoyo, and Margono Setiawan. 2013. "The Role of Customer Value on Satisfaction and Loyalty (Study on Hypermart's Customers)."

International Journal of Business and Management Invention ISSN (Online 2 (6): 2319-8028.

Utami, H. Y. (2014). Pengaruh Tangible, Empathy, Reliability, Responsivenessdan Assurance Terhadap Loyalitas Pelanggan Berbelanja Pada Toko Tita Di Lubuk Buaya Kota Padang. Economica,3(1). 